\title{
SABER LIBERTADOR: COMPARANDO REALIDADES DAS ESCOLAS DA PENITENCIÁRIA DE SALVADOR E ASSUNÇÃO
}

\section{ARTIGO DE REVISÃO}

SENA, Angela Moraes Cordeiro ${ }^{1}$

CLOUX, Raphael Fontes ${ }^{2}$

SENA, Angela Moraes Cordeiro. CLOUX, Raphael Fontes. Saber Libertador: Comparando realidades das escolas da Penitenciária de Salvador e Assunção. Revista Científica Multidisciplinar Núcleo do Conhecimento. Ano 04, Ed. 10, Vol. 08, pp. 104-133. Outubro de 2019. ISSN: 2448-0959, Link de acesso: https://www.nucleodoconhecimento.com.br/educacao/saber-libertador

\section{RESUMO}

O presente artigo tem como proposito fazer uma análise baseada nas observações e percepções da pesquisadora, mas fundamentada em referências bibliográficas, onde foram utilizados documentos oficiais, entrevistas, livros e publicações científicas com dados estatísticos, sobre a realidade de dois lugares separados geograficamente por $3085 \mathrm{Km}$ de distância, onde serão apresentados algumas considerações comparativas entre a educação ofertada no cárcere na cidade de Assunção, no Paraguai, com a ofertada na cidade de Salvador, no Brasil. Recorreu-se também à reflexão sobre a própria prática, uma vez que o objeto de estudo emerge do cotidiano

1 Mestra em Ciências da Educação, graduada em Licenciatura Plena em Administração, Segunda graduação em Licenciatura em Pedagogia e Lic. Em Matemática , Especialista da Pedagogia Organizacional e Recursos Humanos, Especialista em Docência do Ensino Superior, Especialista em Psicanálise Clínica.

2 Doutorado em Desenvolvimento Regional e Urbano. Mestrado em Desenvolvimento Regional e Urbano. Especialização em Docência do Ensino Superior. Graduação em Licenciatura História. 
de uma militância de educadores prisionais, onde com frequência depara-se com pessoas às quais o direito à educação foi negado .Em virtude do objeto de estudo dessa pesquisa está centralizado nas práticas pedagógicas desenvolvidas nas celas de aula e dos instrumentos legais, que amparam e garantem aos privados de liberdade o acesso e remição de pena pela educação, enquanto cumprem as suas sentenças, sejam no regime aberto, semiaberto ou fechado, é que estas comparações se fizeram necessárias para permitirem a análise de experiências e práticas que vem dando certo. $O$ trabalho traz um relato autobiográfico e versa sobre a necessidade de se ter um olhar mais cuidadoso sobre os conteúdos a serem trabalhados com alunos da EJA em prisões. As comparações foram baseadas no processo educativo, na legislação sobre a questão do direito à educação e sobre a questão das escolas na prisão, assim como também no que elas se assemelham e se diferenciam, tanto nas suas práticas como nas normas e diretrizes que regulamentam o seu funcionamento. Desse modo, através de estudos e da experiência profissional, é que foi construído toda observação, aqui apresentada, sobre os sujeitos e seu espaço educativo dentro da prisão nessas duas cidades. $O$ trabalho também aponta para possibilidade de empoderamento pessoal, desses sujeitos que se encontram em privação da sua liberdade.

Palavras chave: educação no cárcere, Salvador, Assunção, legislação, práticas pedagógicas.

\section{INTRODUÇÃO}

Este é um estudo incipiente, que tem como objeto de investigação as realidades educacionais dentro do cárcere de Assunção no Paraguai, e de Salvador no Brasil, sem deixar de levar em consideração outros aspectos importantes para uma melhor compreensão de toda dinâmica do processo analisado. Por isso, esta pesquisa parte de uma proposta que objetiva inicialmente, compreender a educação paraguaia e brasileira, analisando aspectos sociais, econômicos e políticos que foram determinantes para as duas nações, observando as diferenças e semelhanças para entender a instituição educacional e sua presença dentro do cárcere. O período 
delimitado para essas observações e levantamentos foram do ano de 2016 até o ano de 2019.

Foi um verdadeiro exercício de observação e investigação para tentar fazer esse breve comparativo entre a realidade da EJA em prisões na Penitenciária de Tacumbú em Assunção e na Penitenciária Lemos Brito em Salvador. Interessante também, foi a possibilidade de poder ampliar o conhecimento sobre os costumes e a dinâmica do cotidiano das pessoas nas duas cidades, que em muito contribuiu na pesquisa e na desmitificação de alguns conceitos e ideias equivocadas que o brasileiro tem sobre $o$ Paraguai.

A utilização do método autobiográfico nesta pesquisa, visa colaborar com a ciência da educação, trazendo novas dimensões e conhecimentos sobre o educar na prisão, e principalmente colocar o professor na posição de protagonista de sua formação e do processo de investigação sobre essa formação, que é baseada nas experiências e vivências das interações ocorridas em sala de aula, com alunos privados de liberdade.

O trabalho com narrativas autobiográficas implica a forte participação do indivíduo que, por sua vez, se compromete com o processo de reflexão, já que por meio da sua história de vida profissional, poderá descobrir o que conhece sobre o ensino, como está organizando seu conhecimento e como ele se transforma a partir da experiência. A pesquisa narrativa deve ser entendida como uma forma de compreender a experiência humana. Trata-se de um estudo de histórias vividas e contadas, pois "uma verdadeira pesquisa narrativa é um processo dinâmico de viver e contar histórias, e reviver e recontar histórias, não somente aquelas que os participantes contam, mas aquelas também dos pesquisadores" (CLANDININ e CONNELLY, 2011, p.18).

Para o desenvolvimento desta investigação, houve uma busca de fundamentação em diversos autores que discutem a narrativa autobiográfica no contexto da pesquisa educacional. Destacam-se, dentre outros: Clandinin e Connelly, (2011), Nóvoa (1992), Rubem Alves (2003,2012), Freire (1980, 1992 e 1998), Souza (2004), Arroyo (1992) e Conceição Evaristo $(2006,2014)$. 
O desejo é que esse trabalho sirva para ampliar os conhecimentos sobre as práticas pedagógicas, que se mostraram mais adequadas para se trabalhar com a EJA em prisões. Um outro proposito também é tirar da invisibilidade, uma educação que tem uma contribuição muito significativa para a sociedade, mas que é desconhecida por boa parte da população. Ainda é inquietante perceber o grande número de pessoas que se mostram surpresas ao saberem que existe educação sendo ofertada para pessoas privadas de liberdade. Geralmente sempre questionam para que bandido quer estudar, mostrando total desconhecimento sobre quem são os encarcerados, qual o papel da educação dentro desse espaço, o que a sociedade ganha e perde com essas ações educativas e sobre o que diz a nossa Constituição Federal em relação a esse direito.

Falar de duas cidades em países distintos, na qual uma dessas cidades, gosto por demais, por ser minha terra natal, que é Salvador, e da outra que fui aos poucos aprendendo a gostar, devido a convivência alternada, já que foram muitas idas e vindas, onde todo ano viajava de Salvador para Assunção, durante um período de quase 5 anos de estudo, entre o mestrado e doutorado na Universidade Interamericana, é uma tarefa difícil e ao mesmo tempo prazerosa.

Foram muitas as descobertas num mundo que há alguns anos atrás era totalmente desconhecido para mim, ou melhor, conhecia o País com os olhares e opiniões de outras pessoas e tive um choque de realidade quando fui tendo oportunidade de conhecer mais de perto a arquitetura da cidade, os meios de transporte, a culinária, a cultura, os costumes e principalmente as pessoas e o modelo educacional ao qual os paraguaios estão submetidos.

Durante levantamento de dados sobre a realidade da educação nos dois países, foi surgindo o desejo de se fazer um comparativo entre a educação dentro do cárcere e as atividades pedagógicas desenvolvidas na escolas prisionais que funcionam dentro das penitenciárias observadas. Foram muitas as descobertas sobre o que cada uma vinha desenvolvendo, o que possibilitou algumas analises como : a organização hierárquica de cada escola; de que forma os privados de liberdade são orientados para o retorno aos estudos; como é feito o cálculo para remição da pena, através do 
estudo em cada país; os projetos educacionais aplicados; quem são e como são selecionados os educadores prisionais e a concepção dos profissionais da penitenciária e da comunidade em relação a essa oferta de educação.

Serão necessários apresentar alguns aspectos gerais dos dois países e das duas cidades, para uma melhor compreensão da realidade carcerária e dos sujeitos que lá se encontram privados da sua liberdade. Essas informações irão ajudar principalmente,

no entendimento sobre a diferença nos índices de internos que procuram a escola para darem continuidade aos seus estudos nas escolas que funcionam dentro da penitenciária em Salvador e em Assunção.

\section{FALANDO UM POUCO DOS ASPECTOS SOCIAIS DOS DOIS PAÍSES}

O Brasil e Paraguai tem fortes laços históricos, culturais e geográficos, como a construção da Ponte Internacional da Amizade, da Usina Hidrelétrica de Itaipu e a assinatura do Tratado do Mercosul. Isso representam marcos de fortalecimento dos laços políticos, econômicos e diplomáticos entre os dois países que já passaram por bons e maus momentos.

Um ponto interessante a ser abordado, em virtude das constantes observações, foi perceber como é grande o preconceito no Brasil, com tudo que se vem do Paraguai, por este país ter uma Zona Franca que fica na Ciudad del Este, zona fronteiriça entre os dois países, e vender vários artigos, principalmente os eletrônicos mais baratos, o que fez com que fosse criado o estereótipo de que tudo que vem do Paraguai é falsificado, e de que portanto, nada de lá presta.

Dificilmente os brasileiros param para pensar de qual a verdadeira intenção, sem nenhum conhecimento sobre a economia e os bens produzidos pelo povo paraguaio, de se propagar um discurso de que nada do Paraguai presta. As pessoas vem reproduzindo por décadas essa imagem aqui no Brasil, e repetindo esse mesmo 
discurso, mesmo sem ter lido algo referente ao assunto de fontes seguras ou nunca ter estado ou pisado em solo paraguaio.

Quando a pessoa passa a conhecer o país e conhece outras cidades que não seja só a Ciudad Del Este, como Assunção por exemplo, consegue facilmente estabelecer comparações que comprovam os equívocos cometidos por alguns brasileiros, sobre essa imagem criada do país. E até mesmo a ideia de que o Paraguai é sinônimo de sujeira, muvuca e compras baratas, se torna mais claro, sobre quem de fato são os verdadeiros protagonistas desse cenário.

Paraguai não tem grandes indústrias no setor eletrônico e boa parte do comércio de Ciudad del Este está feito para brasileiros e por brasileiros. Só que jogam culpa da situação nos paraguaios, que geralmente nem viajam de compras para Ciudad del Este. Durante as observações e entrevistas com moradores de Assunção, muitos revelaram que preferiam comprar no centro da cidade, já que os preços eram praticamente os mesmos e sem a muvuca causada por compradores e negociantes de outros países. E muitos dos empregados da lojas que lá funcionam, são brasileiros, sem falar que boa parte dos sacoleiros e camelôs, que atravessam a ponte da amizade, para fazer compras e que sujam a cidade também são brasileiros.

Aos poucos, fui fazendo cada vez mais aproximação com os moradores da cidade de Assunção, a ponto de nas últimas viagens, trocar a hospedagem no hotel para me hospedar na casa de uma família que com muita simpatia, abriram as portas da sua casa para acolher os estudantes brasileiros e aumentar a renda familiar. Fazendo compras no mercado, cambiando moedas, caminhando nas praças, chupando muitas mangas, bebendo tererê, comendo as chipas, empanados, cocido, os assaditos, os picaditos e a sopa paraguaia, fui mergulhando cada vez mais na cultura e no cotidiano da cidade de Assunção. Sem esquecer, é claro, da moqueca com dendê, do caruru, do vatapá, da feijoada e dos saborosos bolinhos do abará e acarajé de Salvador.

No que se refere aos aspectos sociais, os habitantes paraguaios enfrentam vários problemas sociais tanto quanto os brasileiros, como as altas taxas de desemprego; a subnutrição nas regiões mais pobres dos países; a escassez dos serviços de 
saneamento básico, que geralmente não são destinados a maioria das residências , pouco investimento em escolas públicas de qualidade, superlotação nas unidades prisionais e um alto índice de desvio de recursos públicos, envolvendo a superfaturação e a lavagem de dinheiro .

O Brasil é hoje um dos países mais desiguais do mundo com quase $30 \%$ da renda nas mãos de apenas 1\% dos habitantes do país. Em 2017 era o nono país do mundo com a maior desigualdade de renda, segundo o coeficiente de Gini. O que não é muito diferente no Paraguai, que mesmo tendo também, a maior parte da população sem água potável e com dificuldades para se alimentar todos os dias, lidera surpreendentemente a classificação como o país latino-americano onde mais se usam as redes sociais, segundo estudo feito para o EL PAíS pelo Instituto para a Integração da América Latina (INTAL), departamento do BID, e a Corporação Latinobarômetro, quando fazendo uma comparação relativa entre a quantidade total da população do pais com o número de usuários.

Tanto no Brasil quanto no Paraguai o largo uso das novas tecnologias caminham mais rápido que a inclusão social e a igualdade. E quando se trata de oportunidade a uma educação de qualidade, percebe-se que a realização desse grande desejo, são para poucos e custa caro.

Em ambos os países, há um enorme problema de mobilidade, já que o sistema de transporte público não é eficiente, e a facilidade para compra de carros vem fazendo com que a frota cause enormes engarrafamentos nas vias urbanas, transforme a ida e volta do trabalho ou escola, num verdadeiro momento de desprazer, devido ao caos que se transformou o transito. E como não fizeram um eficiente planejamento da infraestrutura para toda essa quantidade de veículos, a falta de paz e educação no trânsito vem causando muitas tragédias.

A qualidade do transporte coletivo urbano é a grande questão das cidades contemporâneas. Mesmo o Brasil com uma frota mais moderna e possuindo em alguns estados, um sistema de metrô e trens, não consegue ofertar um serviço muito diferente, já que os sistemas de transporte urbano nas cidades brasileiras sofrem pela 
má qualidade dos serviços que envolvem superlotação, falta de infraestrutura e problemas de investimento. Pegando por exemplo a cidade de Salvador, só após pressão e críticas da população, foi possível, depois de 14 anos de promessa, inaugurar um sistema de metrô em julho de 2014, durante a copa do mundo no Brasil, e que ainda assim não atende a boa parte da população.

Em termos de segurança, há algo notável em Assunção de ser relatado, que é a inexistência de assalto a ônibus, coisa muito comum nos transportes urbanos brasileiros. Algumas situações também nos chamam atenção, como baixo índice de roubo a pedestres e assaltos residenciais. Tanto que é possível observar, de forma quase incrédula, o hábito que alguns moradores ainda têm de dormirem com a porta destrancada, ou de deixarem o carro no estacionamento de um aeroporto, por exemplo, com a chave na ignição, saírem para recepcionar a pessoa que chegou de viagem, e retornar tranquilamente para o carro, com a certeza de que tudo estará no seu devido lugar. Algo impensável no Brasil.

Há também uma diferença na legislação dos dois países no que diz respeito ao porte de arma pelos cidadãos. Enquanto no Brasil, ainda é proibido a compra e uso de armas pelos cidadãos, a legislação paraguaia é realmente uma das menos restritivas da América do Sul, pois qualquer cidadão paraguaio pode comprar uma arma. Bastando apresentar documentos, emitida pela Policia Nacional e realizar um teste técnico de conhecimento básico.

Quando comparamos a qualidade de vida do Paraguai com a do Brasil, percebemos que a diferença está em pequenos hábitos, como por exemplo, o momento da sesta no trabalho, após o almoço. Praticamente, todo comercio para, ou fecha as portas as 12:00h e só retorna lá pelas 14:00h ou 15:00h. Uma prática saudável, que há muito tempo foi abolida do cotidiano dos trabalhadores brasileiros, que devido a distância entre casa e trabalho, o que faz com que a relação entre tráfego e tempo de viagem seja grande, acabam almoçando próximo ou no próprio trabalho.

A taxa de expectativa de vida para os paraguaios em 2017, segundo fontes do CIA World Factbook, era de 77,2 anos, sendo 74,5 para os homens e 80 para as mulheres. 
E no Brasil, segundo o Instituto Brasileiro de Geografia e Estatística (IBGE), a expectativa de vida ao nascer, em 2019, será de 76,5 anos, sendo de 80 anos para mulheres e de 73 anos para os homens.

Alguns dados sobre a situação econômica do Paraguai, apresentando pelo indicador econômico em 2017, mostra que o país que foi visto durante muito tempo como o primo pobre da América do Sul, apareceu em Davos, no Fórum Econômico Mundial, como a grande estrela da região, já que em menos de uma década, a economia paraguaia se reinventou, conseguiu atrair investimentos estrangeiros e crescer com o apoio do agronegócio, chegando a experimentar um crescimento extraordinário de $14 \%$, enquanto o Brasil cresceu $2,3 \%$.

Analisando os valores pagos do salário mínimo em cada país, vemos que oficialmente, enquanto no Brasil o valor é de $R \$ 998,00$ reais, no Paraguai paga-se pelo mínimo valor aproximado de $\mathrm{R} \$ 1350,00$ reais que na moeda guaranis são de 2.112 .562 Gs. Apesar desse valor maior, a legislação Paraguai permite que se pague um valor menor as empregadas domésticas, ou seja, que o salário mínimo das domésticas seja a metade do salário mínimo oficial, o que aqui no Brasil é proibido oficialmente.

Uma outra coisa, muito importante, e que nos chama atenção é o valor do imposto pago sobre todas as transações de compra e venda no Paraguai, que é bastante simplificado e se chama IVA (Imposto de Valor Agregado) e tem teto de 10\%. No Brasil o imposto de consumo, varia, há produtos que pagamos mais de $20 \%$ em carne e mais de 50\% em gasolina. No Paraguai, o valor do imposto ainda é reduzido, de $10 \%$ para 5\% para produtos de cesta básica e alguns de farmácia. E o imposto na bomba do combustível é $0 \%$ e na educação também $0 \%$. Como para outras coisas o imposto gira em torno dos $10 \%$, muito menor do que conhecemos da realidade brasileira, há enorme facilidade em empreender.

Aqui no Brasil a carga tributária é muito grande para os trabalhadores, não existe nada que se tenha $0 \%$. Paga-se imposto demais e retorno de menos. Quando se faz a conta, o indivíduo trabalha 5 meses para pagar de impostos ao governo. São mais de 90 tributos em vigor no país. 
Segundo o IBPT (Instituto Brasileiro de Planejamento e Tributação), o brasileiro gasta uma média de 150 dias por ano trabalhando só para pagar impostos. A gasolina mesmo tem $56,09 \%$ de imposto no preço, a mensalidade de uma universidade tem $26,32 \%$ e os produtos da cesta básica variam de carga tributária. O açúcar tem $30,60 \%$, enquanto o feijão e arroz tem $17,24 \%$. Já a cachaça $81,87 \%$ e o cigarro $80,42 \%$. Para medicamento a taxa é de $33,87 \%$.

O Brasil é o único país falante da Língua Portuguesa nas Américas, e Paraguai é um país bilíngue, que oficialmente se falam Guarani e Espanhol. O Presidente da República tem basicamente os mesmos luxos dos monarcas que habitavam o Palácio de Versalhes, com os benefícios tecnológicos e gastronômicos do século 21. Só que há diferenças sobre ganhos e vantagens em cada país, pois enquanto o do Brasil oficialmente tem o salário aproximadamente de $R \$ 33.000,00$ (trinta e três mil reais), o do Paraguai ganha algo em torno de $\mathrm{R} \$ 24.000,00$ (Vinte e quatro mil reais) e com direito a alguns benefícios que o presidente brasileiro tem.

Quanto ao descaso com políticas públicas sérias que respeitem e envolvam melhoria da saúde e educação para a população, as ações e articulações dos dois governos são muito parecidas. E não é só no Brasil, que temos a corrupção instituída e espalhada por toda a sociedade, conforme resultados de investigações realizadas pelo Ministério Público e expostas através da mídia para a população. A vontade de levar vantagem também é cultural em ambos os países, assim como a cobrança de propina em alguns setores. As eleições no Paraguai são de $5 \mathrm{em} 5$ anos, sem direito a reeleição, e no Brasil são de 4 em 4 anos e com direito a reeleição.

\section{A POLÍTICA EDUCACIONAL E OS INSTRUMENTOS LEGAIS DOS DOIS PAÍSES}

Dentro do rol dos direitos humanos fundamentais encontra-se o direito à educação, amparado por normas nacionais e internacionais, por se tratar de um direito essencial para o processo de desenvolvimento individual, próprio à condição humana. Por isso, conhecer a política educacional e o que diz as leis de cada país, possibilita 
compreender de que forma se dar o processo educativo, para analisarmos de modo mais consistente, como essa educação se articula nessas duas sociedade.

Constituição Federal Brasileira de 1988, afirma no Artigo 205, que "A educação, direito de todos e dever do Estado e da família, será promovida e incentivada com a colaboração da sociedade, visando ao pleno desenvolvimento da pessoa, seu preparo para o exercício da cidadania e a sua qualificação para o trabalho". Estabelece ainda no Artigo 208, Inciso I, a garantia da "educação básica obrigatória e gratuita dos 4 (quatro) aos 17 (dezessete) anos de idade, assegurada inclusive sua oferta gratuita para todos os que a ela não tiveram acesso na idade própria". (Redação dada pela Emenda Constitucional no 59, de 2009).

E na Lei de Execução Penal Brasileira (n.ำ 7.210/1984), define em seu Artigo 1ํ, que o objetivo da execução penal é efetivar as disposições de sentença ou decisão criminal e proporcionar condições para a harmônica integração social do condenado e do internado. Define ainda no Artigo 10 que a assistência ao preso e ao internado (no qual se inclui a assistência educacional) é dever do Estado e objetiva prevenir o crime e orientar o retorno à convivência em sociedade.

A educação no Capitulo VII da Constitución de la República de Paraguay de 1992, aborda nos Artículo 73 "Toda persona tiene derecho a la educación integral y permanente [...].", no Artículo 74 - "Se garantizan el derecho de aprender y la igualdad de oportunidades al acceso a los beneficios de la cultura humanística, de la ciencia y de la tecnología, sin discriminación alguna", e no Artículo 75 - La educación es responsabilidad de la sociedad y recae en particular en la familia, en el Municipio y en el Estado.

Esses três artigos aliados ao artigo 76 que fala sobre as obrigações dos estados para oferecer educação a população, "La educación escolar básica es obligatoria. En las escuelas públicas tendrá carácter gratuito", é muito parecido com o que diz na Constituição Brasileira no artigo 205, onde a educação deve ser direito alcançados por todos, e o Estado e da família tem a responsabilidade de fazer com que essa 
educação aconteça, visando sempre o desenvolvimento da pessoa, seu preparo para o exercício da cidadania.

A educação é retratada em outros dispositivos legais tanto do Brasil quanto do Paraguai, como na Lei 1264 que é a Ley General de Educación Paraguay, que estabelece:

Artículo 1‥ - Todo habitante de la República tiene derecho a una educación integral y permanente [...]

Artículo 2ํㅡ. - El sistema educativo nacional esta formulado para beneficiar a todos los habitantes de la República [...] Artículo 3ํ.- El Estado garantizará el derecho de aprender y la igualdad de oportunidades de acceder a los conocimiento y a los beneficios de la cultura humanística. Artículo 4ํ.- El Estado tendrá la responsabilidad de asegurar a todo la población del país el acceso a la educación y crear las condiciones de una real igualdad de oportunidades.

Essa Lei 1264, possui alguns elementos comuns com os 120 artigos da Lei 9394/96 que é a Lei de Diretrizes e Bases da Educação Brasileira (LDB), que logo no seu capitulo I, estabelece dos fins da educação e no Art. 4ํำ do dever do Estado com educação escolar pública.

A falta de investimentos na educação, é um problema sério nos dois países. Se de um lado temos um país com grande reservas naturais, com pouco aproveitamento das potencialidades humanas e baixíssima oferta de oportunidades aos mais pobres, devido a lama de corrupção no qual o país está mergulhado, por outro lado, o país vizinho, que por ser menor e ter menos recursos, vem padecendo, para pôr em prática uma reforma educacional que começou em 1989, devido ao longo ciclo autoritário que permaneceu o país, conforme coloca Rivarola:

Una característica resaltante de la transición política que se inició en 1989 fue la reforma educativa. A diferencia de la mayoría de los países de la región que en las últimas décadas han puesto en marcha procesos de reforma educacional, el caso paraguayo se distingue por darse dicha iniciativa con el trasfondo de un largo ciclo autoritario. En tal contexto, la idea de democratización tuvo una presencia gravitante tanto en la construcción de un nuevo sistema educativo como en el papel central [...] la reforma paraguaya insiste en igual medida en lograr una educación 
que permita que cada ciudadano adquiera la competencia para insertarse al cambiante y complejo mundo del trabajo. El estudio ofrece también referencia sobre las motivaciones y participación de los principales actores involucrados y los cambios de orden institucional. (RIVAROLA, 2000, p.01).

Historicamente o Paraguai sofre o peso de duas décadas perdidas, sem reformas e sem experiência democrática. Isso acabou influenciando nos tímidos dados sobre a educação paraguaia. Ainda hoje, é um assunto que decorre de uma negligência de conhecimento, sobre os estudos que geralmente são feitos e abrangem a temática América Latina, pois nada é visto em publicações sobre o MERCOSUL, ao qual o país também faz parte. Percebe-se que o Paraguai, apesar de integrar o território Latinoamericano, dificilmente é mencionado na literatura e nos estudos que envolvem o continente

Para compreender a política de educação no Paraguai e no Brasil, de modo consistente devemos analisar a forma como se articulam com a sociedade. Vimos que em ambos, está claro nas suas constituintes a responsabilidade do governo pela oferta da educação a população. Sendo que no Brasil, a educação básica, segundo o artigo 208 é obrigatória e gratuita dos 4 (quatro) aos 17 (dezessete) anos de idade, E no Paraguai, no artigo 32 da Ley General de Educación, a educação escolar básica também compreende 9 anos e é obrigatória, incluindo o pré escolar.

A dinâmica do professor do ensino médio na escola pública no Brasil, envolve uma roupagem diferenciada do Paraguai, pois no Brasil o professor fica lotado numa escola, para lecionar determinada disciplina numa carga horaria semanal de 20 ou 40 horas. E mesmo tendo seu salário atrelado a quantidade de horas lecionadas, geralmente o máximo de escola que este professor ficara vinculado para ensinar a sua disciplina, serão duas escolas se ele for professor de 40 horas.

Esse processo é um pouco diferente nas escolas do Paraguai. Geralmente o professor só fica vinculado a uma ou duas escolas se ele for professor do ensino básico. Caso seja professor do ensino médio, é considerado um professor horista, e a forma de pagamento também é diferenciada, pois para completar a sua carga horária, ele acaba circulando em várias escolas que tem o ensino médio, para ensinar a disciplina para 
qual foi capacitado, conforme relato de um professor experiente em dar aulas nas escolas em Assunção:

Soy paraguayo y graduado en Filosofía de la Educación, Teología y Maestría en Ciencias de la Educación y a menos de un año me retiré como profesor, después de 25 años de clase. Ya he enseñado en la enseñanza media y universitaria, nunca he enseñado en lo primario. Los estudiantes universitarios, que enseñé, eran para ser futuros docentes. Trabajé en escuelas privadas y públicas de Asunción. Aquí el profesor que enseña en el nivel medio, gana como horista y tiene que rodar en varias escuelas, él no queda fijo a una determinada escuela, como sucede con los profesores de la enseñanza básica. (Prof. Daniel González Anzoateguiv).

Em relação a quantidade de alunos na sala, a realidade é muito parecida nos dois países, e conforme o Professor Daniel, existem escolas nas zonas rurais onde é possível ver mais de 50 alunos na sala. Um dado preocupante, foi relacionado a uma situação do seu país, que não é a mesma do Brasil, que é a questão do Paraguai ser um país bilíngue, onde oficialmente se falam a língua Espanhol e Guarani, mas que segundo o professor, há muita diferença entre a escola na cidade e no interior, onde as dificuldades são bem maiores.

O professor Daniel aproveitou e citou como exemplo, as escolas que funcionam na zona rural, onde tem muitas que os alunos não sabem falar Casteliano, e ai todas as aulas são dadas na língua Guarani. Ele disse que os alunos entendem um pouco do Casteliano, mas não dominam. E que na cidade, como em Assunção, o processo é inverso, todos falam e dominam o Casteliano, e quase não sabem falar o Guarani, mas entendem. "Eu falo Guarani porque aprendi no dia-a-dia e em casa com meu pai, mas nunca estudei o guarani." (Prof. Daniel Gonzalez Anzoateguiv).

Corroborando com o que foi dito pelo professor paraguaio, Rivarola coloca o seguinte, sobre essa questão nas escolas rurais:

Hasta fines de la década del sesenta, el sistema educativo paraguayo seguía manteniendo gran parte de sus características históricas. Es decir, un fuerte predominio de las escuelas localizadas en zonas rurales o semi-urbanas, altas tasas de repitencia y deserción, una pronunciada diferencia entre los niveles de calidad entre las unidades educativas 
rurales y las urbanas, limitada cobertura de la enseñanza media, alta concentración de recursos en la Capital, la diferencia por género en el acceso y retención en la escuela, fuerte proporción de docentes no profesionalizados, alta proporción de escuelas incompletas, escasa atención a las modalidades lingüísticas de la población escolar. (RIVAROLA, 2000, p.08).

A reforma educacional no Paraguai, pelo que está exposto acima, encontrou diversas barreiras, principalmente as condições estruturais, cujo sistema produtivo era de natureza marcadamente agrária. Isso influenciava no lento crescimento urbano e no processo educativo, já que com a expansão urbana, a concentração de recursos ficou direcionada as escolas da capital, sendo dada pouca atenção as escolas rurais e consequentemente as modalidades linguísticas dessa população escolar, que até hoje faz resistência ao uso do idioma Espanhol.

Quanto ao acesso as universidades públicas no Brasil atualmente, boa parte dos alunos, conseguem através do resultado de pontos realizados na prova do ENEM (Exame Nacional do Ensino Médio) ou realizando vestibular nas universidades e faculdades particulares que ainda não aderiram ao ENEM, ou aderiram de forma parcial. Isso acontece porque o número de vagas ofertadas nos cursos universitários, geralmente não atende à demanda existente

Na legislação do Paraguai, não tem ainda essa exigência, do aluno ter que prestar um vestibular, mesmo que o aluno seja submetido a fazer uma prova especifica aplicada por alguma instituição de ensino superior, não existe uma obrigação legal. Tanto que na maioria das Universidades particulares, o aluno após concluir o seu ensino médio, basta verificar primeiro se tem vaga para o curso desejado e se terá dinheiro para pagar o curso, inclusive o de medicina, que tem concorrência altíssima no Brasil.

Isso não significa que no Paraguai são ofertadas mais vagas nos cursos universitários do que no Brasil, é importante entender um fator que afeta diretamente a escala do sistema de ensino superior no Paraguai, "que é o restrito do sistema de ensino secundário[...] a taxa de matrícula no ensino médio é a mais baixa da América Latina e uma das mais baixas do mundo". (RIVAROLA, 2000, p.08). Essa alta seletividade 
do sistema de ensino médio, faz com que, segundo Rivarola, apenas um em dois alunos que iniciam o ensino médio completa o ciclo completo.

\section{O DIREITO A EDUCAÇÃO DOS PRIVADOS DE LIBERDADE DE SALVADOR E ASSUNÇÃO}

Abordar questões que envolvam leis e a garantia de direitos a pessoas privadas de sua liberdade exige uma visão mais dilatada sobre a situação analisada, sendo assim, não podemos fazer afirmações seguindo somente a nossa ótica, ou sobre micro observações, enquanto na realidade existe uma emaranhada rede de ligações entre países que fazem ou não fronteiras entre si.

Por mais que nas normas contidas no direito internacional dos direitos humanos enfatize que cada sujeito privado da sua liberdade, deve ser tratado com humanidade e respeito que merece a dignidade inerente da pessoa humana, onde o estado deve fornecer condições de qualidade nas instalações, bem como nos serviços de saúde, alimentação e educação, o que mais se vê nos presídios, principalmente nos dos países da América do Sul, são descasos, mal tratos e superlotação. O que vem exigindo uma série de reformas, e por mais mudanças que se façam, ainda assim permanecem intactos os vícios dos sistemas penitenciários latino-americano, conforme apontado no documento sobre os Direitos Fundamentais da Pessoa Privada de Liberdade:

Aunque con distintos niveles de intensidad y éxito, este movimiento de reforma procesal penal parece dirigirse a asegurar mejoras en la efectividad de la sanción penal y, al mismo tiempo, el respeto de las garantías de los imputados y procesados. Con todo, esta serie de reformas ha dejado casi intactos los principales vicios de los sistemas penitenciarios latinoamericanos. La mantención de condiciones carcelarias indignas, las prácticas de tortura, tratos crueles, inhumanos y degradantes en contra de adultos y adolescentes privados de libertad, la falta sistemática de jueces de control de penas y de mecanismos judiciales. (Derechos Fundamentales de los Privados de Libertad, 2010, p.180).

No Brasil, o direito à educação do preso está disciplinado de maneira direta ou transversal na Constituição Federal, no Código Penal (lei 2.848/40 e posteriores 
alterações), na Lei de Execução Penal (lei ํo. 7.210/84), nas resoluções e orientações do Conselho Nacional de Política Criminal e Penitenciária (CNPCP) e de maneira particular nos textos normativos penitenciários de cada unidade da federação

E foi a partir da Constituição de 1988, chamada de Constituição Cidadã, que se verifica a edição de várias leis, decretos, portarias e resoluções para dar cumprimento aos direitos sociais por ela garantidos a todos os cidadãos .Entre essas leis, vale destacar a Lei 9.394/96, de Diretrizes e Bases da Educação Nacional, a Lei 12.852/13, Estatuto da Juventude, a Lei 12.433/11, que altera a Lei 7.210, que trata da execução penal, para incentivar o estudo nos presídios, a Resolução 02/10 do Conselho Nacional de Educação ( $\mathrm{CNE}$ ), que trata da educação nos presídios, além de uma série de decretos voltados para a garantia do direito do preso à educação.

Dentro da legislação estadual mereceu atenção especial o Plano Estadual de Educação no Sistema Prisional da Bahia, que foi estabelecido na Resolução CEE № 43, de 14 de julho de 2014. Os Planos Estaduais (e Distrital) de Educação nas Prisões, foram elaborados a fim de executar o Plano Estratégico de Educação no Âmbito do Sistema Prisional - PEESP, em conformidade com o Departamento Penitenciário Nacional - DEPEN, que em focado no papel da escola pública e dos espaços educativos como estratégia fundamental de combate às desigualdades e promoção da equidade no sistema prisional brasileiro. Esses Planos foram elaborados, em conjunto, pelas respectivas Secretarias de Educação (SEC - BA) e da Secretaria de Administração Penitenciária e Ressocialização (SEAP - BA).

No Paraguai, esse direito também está amparado Constitución de la República de Paraguay, 1992, Ley General de Educación -Paraguay :1264, com alguns indícios no Codigo Penal de Paraguay Ley №. 1.160/97 e na Ley № 5.162, Código de Ejecución Penal Para la República del Paraguay para os jovens infratores.

A importância da oferta da educação também é trata com bastante clareza, num pacto realizado entre diversos países, chamado de Direitos Fundamentais dos Privados de Liberdade, onde diz que a educação deve ser direcionada para o pleno desenvolvimento da personalidade humana e do senso de dignidade, reconhecendo acima de tudo, que a educação é um direito de todos, sem nenhuma distinção: 
Los Estados Partes en el presente Pacto reconocen el derecho de toda persona a la educación. Convienen en que la educación debe orientarse hacia el pleno desarrollo de la personalidad humana y del sentido de su dignidad, y debe fortalecer el respeto por los derechos humanos y las libertades fundamentales. Convienen asimismo en que la educación debe capacitar a todas las personas para participar efectivamente en una sociedad libre, favorecer la comprensión, la tolerancia y la amistad entre todas las naciones: entre todos los grupos raciales, étnicos o religiosos, y promover las actividades de las Naciones Unidas en pro del mantenimiento de la paz. (Derechos Fundamentales de los Privados de Libertad, 2010, p.178).

Como podemos perceber a educação transpassa os murros da prisão, não como um benefício para os presos, mas sim como um direito garantido por lei, que inclusive também está no Estatuto da Criança e do Adolescente (Lei 8.069 no dia 13 de julho de 1990), na segunda parte, que trata dos órgãos e procedimentos protetivos, com a aplicação de medidas sócio-educativas do Conselho Tutelar.

Isso é similar a Ley № 5.162/14, Código de Ejecución Penal para la República del Paraguay, que é direcionada aos jovens e adolescentes infratores que no Capítulo II, trata da Ejecución de Las Penas Y Medidas Penal, que tem como objeto, conforme consta no seu Artigo 17, promover a educação dos adolescentes a quem se impõe uma medida social, Educacional, correcional ou custodial. Sempre levando em consideração suas necessidades e buscando o desenvolvimento integral do mesmo, bem como o exercício e o pleno gozo de seus direitos e garantias inerentes, garantindo o contato permanente com sua família.

Já no Código Penal do Paraguai, que é a LEY №. 1.160/97, não se fala muito sobre direito a educação do preso, e sim sobre o direito ao trabalho. Mas deixa claro que outros direitos, estão fixados na Lei Penitenciária do país, quando coloca no inciso 4 do artigo 40, que "En cuanto a lo demás, en especial la forma en que el condenado administre el fruto de su trabajo, se aplicará lo dispuesto en la ley penitenciaria."

No Código Penal Brasileiro, é possível ver a relevância dada a educação dentro do sistema prisional, onde o preso poderá ter remição tanto por trabalho quanto para estudo, segundo Art. 126, onde o condenado que cumpre a pena em regime fechado 
ou semiaberto poderá remir, por trabalho ou por estudo, parte do tempo de execução da pena. (Redação dada pela Lei oㅜ 12.433, de 2011).

\section{O SABER QUE LIBERTA}

Falando um pouco sobre os trabalhos educativos desenvolvidos pelo Colégio Professor George Fragoso Modesto e pelo Centro Educativo Virgen de la Merced, de Tacumbú, que funcionam respectivamente dentro do Complexo Penitenciário de Salvador e de Assunção, percebemos que os alunos valorizam a oportunidade de começarem ou retornarem aos estudos, enquanto estão privados da sua liberdade, o lamentável é que nem todos conseguem ver dessa forma.

Apesar da barreiras, os professores das duas escolas vêm conseguindo desenvolver algumas práticas pedagógicas que conseguem influenciar positivamente na mudança de pensamento e atitudes dos alunos. Para os que não eram alfabetizados, os relatos são parecidos, pois ficam deslumbrados quando começam a ler as primeiras palavras e analisar o antes e depois, onde há pouco tempo as correspondências familiares que recebiam eram apenas um amontoado de letras mortas, lidas de favor pelos colegas de cela. "A educação crítica é a futuridade revolucionária. Ela é profética - e como tal, portadora de esperança - corresponde à natureza histórica do homem. Ela afirma que os homens são seres que se superam" (FREIRE, 1980, p.81)

Ao compararem como se encontram hoje, alfabetizado e dando continuidade aos estudos, percebem que suas letras ganharam contornos mais nítidos, e podem fazer algo tão desejado: uma leitura autônoma. Muitos dizem que se sentem agora libertados, mesmo estando encarcerados, mas que não morreriam mais na ignorância e não passaria mais vergonha na hora de assinar algum documento enviado pelo juiz. Isso nos mostra algo muito parecido com o que Freire coloca:

A educação critica considera os homens como seres em devir, como seres inacabados, incompletos em uma realidade, igualmente inacabada e juntamente com ela. Por oposição a outros animais, que são inacabados, mas não históricos, os homens sabem-se incompletos. Os homens têm consciência de que são incompletos, e assim, nesse estar inacabados e na consciência que disso têm, encontram-se as raízes 
mesmas da educação como fenômeno puramente humano. (FREIRE, 1980, p.81).

Um aluno, orgulhoso por ter ampliado sua possibilidade de comunicação e interação com o mundo, relatou que o seu advogado, ficou surpreso, ao vê-lo após 4 anos acompanhando-o, trocar o carimbo do dedo e assinar seu nome, pela primeira vez informações sobre a sua sentença. E ao perceber a cara de surpresa do advogado, ele simplesmente se levantou e disse: Estou estudando!

São esses e outros episódios, que fazem com que os professores que escolheram aceitar o desafio de ensinar na prisão, tanto em Salvador como em Assunção, busquem trabalhar com uma educação problematizadora, que estimulem seus alunos a pensarem de que são capazes de refazer a sua história, mesmo diante de uma sociedade que acredita que o seu futuro já está predeterminado, por serem presidiários. Exatamente por isso, que "a educação problematizadora - que não aceita nem um presente bem conduzido, nem um futuro predeterminado - enraíza-se no presente dinâmico e chega a ser revolucionária" (FREIRE, 1980, p.81)

Inclusive para os que já conseguiam fazer um pouco de leitura, também mudam as letras criadas para composição de rap ou frases de ódio como protesto. Onde antes se via, entre os internos que frequentam à escola, frases sobre crime ou de vingança contra os agentes ou policiais, passaram a escrever frases exigindo justiça e igualdade de direitos para todos, e um tratamento mais digno para os infratores da lei. Sem privilégios para uns e para outros não, a começar por quem deveria dar exemplo. Quando fazem composições homenageando a família, a escola e todos que lá trabalham mostram que há espaço para outros pensamentos.

E são através das cartas, dos argumentos, das mudanças de comportamentos e redações, que alguns alunos foram até premiados em concursos literários. Tanto os professores quanto os familiares e outras pessoas do convívio com o aluno, conseguem perceber o avanço que aos poucos eles vem fazendo. Isso mostra o quanto conseguiram internalizar das aprendizagens que veio sendo construídas através da escuta e do olhar cuidadoso durante os trabalhos desenvolvidos em sala. Segundo Freire, "o caráter inacabado dos homens e o caráter evolutivo da realidade 
exigem que a educação seja uma atividade continua. A educação é deste modo, continuamente refeita pela práxis. Para ser, deve chegar a ser" (FREIRE, 1980, p.81)

Nas duas escolas, todo conteúdo pedagógico é ensinado por professores capacitados e com formação superior nas áreas específicas das disciplinas que lecionam. A única disciplina que é ensinada na escola de Assunção que não é ensinada na de Salvador é a Língua Guarani. No geral os conteúdos são trabalhados de forma contextualizada com a realidade dos alunos, respeitando os saberes que já trazem, estando sempre implícitos nas atividades lúdicas, propostas na pedagogia de projetos, priorizando uma avaliação contínua e processual.

Os educadores prisionais em Salvador são na sua maioria funcionários públicos, concursados e estão ligados a Secretaria de Educação. Em Assunção, os educadores prisionais são na sua maioria selecionados e enviados pelo Ministério de Educação e Cultura (MEC) à Penitenciária, onde se apresentam ao diretor da unidade prisional e ao diretor da escola, para em seguida assumirem as suas salas de aula.

O diretor da Penitenciária de Tacumbú, ao falar desses projetos, reafirmou a importância e o impacto do desenvolvimento dessas práticas pedagógicas no chão de uma prisão, disse que o resultado é visível, e acrescenta ainda que:

El punto positivo en tener una escuela dentro de la cárcel es ver que los alumnos tienen instrucciones pedagógicas que además de prepararlos para el mundo del trabajo y para la vida, también ayuda a evitar situaciones negativas, como tumulto, problemas y rebeliones en la cárcel. En relación a las prácticas pedagógicas veo buen desarrollo de los alumnos que se hacen presentes en las clases. Los internos que estudian tienen un progreso muy alto, con cambios significativos para mejor. Tiene una ley que baja la pena cuando se está estudiando. El estudio da la posibilidad de salir más rápido en libertad. (Abog. Anildo Caballero Otarga - Diretor da Penitenciária de Tacumbú).

Mesmo com todo empenho dos educadores e diretores, a realidade dos presídios de Salvador e Assunção, onde a superlotação, descaso e negação de muitos direitos básicos são frequentes, reforça a certeza de que o sistema prisional é ineficaz e a cada dia que passa vai ficando mais precária a situação dentro desses estabelecimentos. O que faz com que o convívio dos detentos se torne cada vez mais 
difícil e complicado, tendo em vista a falta de educação e pouca instrução de boa parte do corpo carcerário, que às vezes mostram descontentamento ou resistência com a presença do professor.

Até o momento, não existe nenhum registro de atentado ou ameaça à integridade física do professor na escola de Salvador, pois os alunos tem um total respeito e admiração pela presença deles naquele espaço. E para os que não recebem visita da família e não podem ter acesso a rádio ou televisão, as novidades e acontecimentos ocorridos na cidade, extramuros, só são possíveis de serem enxergadas através do olhar do professor.

Isso exige um cuidado redobrado com tudo que for dito pelo professor, para evitar situações embaraçosas. Essa realidade é um pouco parecida na escola de Assunção, onde segundo o Diretor "los reclusos tienen mucho respeto por los profesores y nunca hubo ninguna situación de ataque o amenaza de alumno al profesor". Então o respeito mutuo, é a ferramenta principal, para continuidade da educação dentro de um sistema prisional.

Apesar do grande interesse pela merenda escolar, muitos alunos da unidade prisional de Salvador, já demostraram que estudariam com ou sem a merenda, visto que, a escola levou vários meses sem receber verba do governo, o que impossibilitou a oferta da merenda, e mesmo assim as salas permaneceram cheias. Algo um pouco parecido com os alunos da unidade prisional em Assunção, já que percebem que são muitos querendo estudar, mas como o espaço físico é pequeno, muitos precisam ficar ainda aguardando oportunidade. Sem falar nas vantagens de quem estuda, para quem não estuda e não aceitam serem evangélicos na Penitenciária de Tacumbú. É gritante a diferença dos espaços ocupados entre os internos, onde os que ficam de fora da escola, se vê mais uma vez excluído pelos excluídos.

O Colégio Professor George Fragoso Modesto, conta com uma equipe gestora composta por um diretor, 3 vice-diretoras, 1 secretaria e 2 coordenadoras pedagógicas, além do pessoal da secretária, merendeiras e pessoal de apoio. No total são 46 docentes trabalhado nos três turnos, para atender entre 750 a 1200 alunos (já 
que durante o ano há muitas variações), localizados em unidades prisionais diferentes. Das 10 unidades prisionais do Complexo Penitenciário de Salvador, a escola se faz presente em 8 unidades, não atendendo ainda a outras 2 unidades restantes devido à falta de espaço físico para adaptação de sala de aula, segundo direção.

O Centro Educativo Virgen de la Merced, na Penitenciária de Tacumbú, conta também com um diretor, coordenador e um facilitador. Sendo que esse facilitador, é um dos privados de liberdade, avaliado pela direção prisional com bom comportamento, que fica responsável pela organização dos alunos que querem estudar e de dar suporte ao diretor e professores sobre coisas pertinentes ao espaço educacional. O Diretor Otarga, acrescenta que hoje, "el complejo penitenciario está.com una superpoblación de más de 2000 presos, pues tiene capacidad para 1600 presos, pero está con 3900, y no tiene donde colocar tanta gente". Também relatou que às vezes chegam presos que começam a roubar os demais, e por falta de espaço de onde coloca-los, eles são obrigados a liberar esse preso provisório, para não causar uma situação mais agravante na cadeia.

No total o Centro Educativo Virgen de la Merced, conta com 25 professores na escola, para atender a todos os alunos que estão matriculados em distintos pavilhões. $E$ apesar do complexo Penitenciário de Tacumbú possuir 30 pavilhões, não foi possível colocar sala de aula em cada pavilhão, devido a grandeza e complexidade do lugar. Então, segundo o Diretor Anildo Otarga, a escola está organizada, para que os professores trabalhem em 20 salas de aulas. E nos pavilhões que não tem sala de aula, os alunos são direcionados para os pavilhões onde acontecem as aulas, inclusive os alunos que estão cursando a universidade, que também tem espaço próprio.

Em termos de modalidade de ensino, ambas as escolas adotaram a Educação de Jovens e Adultos. Na escola de Salvador, os alunos se matriculam no Tempo Formativo I (alfabetização até 5a ano), Tempo Formativo II (6ำ ao 9ำ ano) e Tempo Formativo III (Ensino Médio). E na escola de Assunção, a escola oferece o Escolar Básico o Escolar Secundário, tendo também uma base da Universidade para oferecer 
o Ensino Superior. O dinamismo para logística dos internos conseguirem frequentar a universidade, acontece através da unidade instalada da universidade dentro da penitenciaria.

\section{A REMIÇÃO POR TEMPO DE ESTUDO NAS DUAS PENITENCIÁRIAS}

Além da contribuição intelectual, a educação ajuda indiretamente na não superlotação das cadeias, assim como também o trabalho, visto que a presença dos alunos em ambas as penitenciárias serve para ajudar o aluno privado de liberdade na remição da sua pena. Essa conta de horas estudadas para remição aqui no Brasil, consta na Lei de Execuções Penais, que é a Lei no 12.433, de 29 de junho de 2011, que altera a Lei no 7.210, de 11 de julho de 1984 (Lei de Execução Penal), para dispor sobre a remição de parte do tempo de execução da pena por estudo ou por trabalho, já que na lei anterior (Lei $n^{\circ} 7.210$ ) a remição era só pelo trabalho.

No Paraguai também existe diminuição da pena, pelo trabalho e pelo estudo, mas a contagem das horas é um pouco diferente da realizada de acordo com a lei brasileira. Segundo o Diretor Anildo Otarga, a contagem para remição é feita da seguinte maneira:

Tiene una ley que baja la pena cuando se está estudiando. El estudio dar la posibilidad de que la persona presa salir más rápido en libertad. La cuenta de la remisión por estudio se hace de la siguiente manera: un año de estudio equivale a más o menos a 30 días de pena.. Para el trabajo, cada año abate 90 días. (Abog. Anildo Caballero Otarga - Diretor da Penitenciária de Tacumbú)

Frequentando as aulas enquanto estão privados de liberdade na penitenciária, os detentos ganham então, redução do período de condenação. No Paraguai cada 1 ano de estudo abate 30 dias da pena, e no Brasil, a cada doze horas de frequência escolar, um dia será abatido da pena.

Enquanto no Brasil esse direito está previsto pela Lei de Execução Penal desde 2011, no Paraguai, segundo o Advogado Criminal Joseg Oquila, que acompanha os 
processos dos presos da Penitenciária de Tacumbú, e toda semana está lá para dar assistência, "no existe una Ley específica para Remisión por estudio para preso aquí en Paraguay, pero se toma como parámetro lo que dice los Derechos Humanos y sus artículos. Tomando y adaptando uno de los artículos para poder implementar para los presos que aquí estudian." Então existe uma prática para remição da pena por estudo no Paraguai, mesmo sem ter uma lei específica, a ação está baseada em artigos sobre o que orienta a Cartilha dos Direitos Humanos.

Interessante que aquí no Brasil, antes da lei ser sancionada para remição por estudo, segundo o Promotor de Justiça do Estado da Bahia (PJ1), "os tribunais e as varas de execuções penais, já vinham admitindo a educação, aproveitando o estudo para remição. E ai a lei veio a reboque, validando uma prática que já vinha sendo adotada". Algo muito parecido com o que vem acontecendo no Paraguai, já que consideram a remição por estudo, sem uma lei específica. E sobre essa questão no Brasil, Sousa coloca:

De plano percebe-se pela alteração no art. 126 da Lei de Execuções Penais pelo qual a remição foi estendida ao preso que estuda. Tal posicionamento já vinha sendo aplicado pelos tribunais superiores (Súmula 341 do STJ) com certa notoriedade em que pese ainda existirem vozes contrárias. Nada mais produtivo do que dar oportunidade aqueles que cometeram crimes de estudar, qualificar-se e, quem sabe assim, efetivamente promover uma reinserção social do custodiado. Não há como negar a importância de oferecer ao apenado uma luz no fim do túnel, uma ocupação, seja um trabalho interno ou externo ou um curso profissionalizante, parece ser uma das poucas soluções para que após cumprir sua reprimenda (sim, um dia ele vai sair da prisão) não se torne mais um reincidente (SOUSA, 2011, p.01).

Hoje a remição pela frequência na escola da Penitenciária de Salvador, tem o mesmo valor da remição pelo trabalho. A lei estabelece que 3 dias de trabalho equivale a 1 dia de pena. Para a educação, o legislador colocou que a cada 12 horas de estudo, equivale a 1 dia de pena. $O$ que o legislador quis de fato fazer, foi tentar conciliar o estudo e o trabalho. Tanto que "a lei 12.433 vai mais além, permite a cumulação de remição por estudo e trabalho $\left(126 \S 3^{\circ}\right)$ desde que compatíveis e continua beneficiando com a remição o apenado que por acidente de trabalho que fique impossibilitado de trabalhar e agora estudar" (SOUSA, 2011.p;01). 
A mesma lei 12.433, complementando as disposições sobre a remição pelo estudo, no $\S 5^{\circ}$ do art. 126 da LEP, acrescido pela lei reformadora, criou uma espécie de bônus ofertado ao sentenciado caso este, durante o tempo de cumprimento da pena, alcance a conclusão de ensino fundamental, médio ou superior, o que the dará direito a acrescer 1/3 (um terço) a mais do tempo remido, conforme mostrado na lei 12.433:

Art. $126-\S 5^{\circ} \mathrm{O}$ tempo a remir em função das horas de estudo será acrescido de $1 / 3$ (um terço) no caso de conclusão do ensino fundamental, médio ou superior durante o cumprimento da pena, desde que certificada pelo órgão competente do sistema de educação.

Vale ressaltar que o principal objetivo da remição da pena pelo estudo é incentivar a recuperação dos sentenciados por meio do seu desenvolvimento intelectual. E o direito a acrescer um terço a mais do tempo remido, é uma "medida conhecida como remição formatura, remição acrescida ou remição da remição e visou dar um maior estímulo ao sentenciado "(SILVA, 2013, p.05).

Há uma grande frustação do aluno, que o tempo todo vem sendo estimulado a estudar e prosseguir nos estudos e quando ele passa no ENEM, se depara com uma triste realidade, que é a de não poder estudar. Sejam por problemas administrativos e burocráticos da segurança penitenciária ou pela falta de uma unidade universitária dentro do Complexo Penitenciário de Salvador. O que já não acontece com os alunos privados de liberdade do complexo Penitenciário de Tacumbú, pois contam com o ensino superior, enquanto cumprem pena, na unidade instalada pela Universidade Metropolitana dentro da penitenciária.

\section{CONSIDERAÇÕES FINAIS}

Nessa pesquisa comparativa, cujo propósito foi fazer alguns levantamentos sobre as propostas educativas do Brasil e do Paraguai, tanto dentro quanto fora dos muros das prisões, para analisar as semelhanças e diferenças entre as realidades vivenciadas pelo privados de liberdade que frequentam a escola, assim como também o cotidiano das pessoas nos dois países, possibilitou uma visão mais ampliada sobre os desafios e possibilidades existentes em cada país. 
Através das observações, vivências, relatos e trocas, foi possível aos poucos, entender o contexto de cada lugar e no que um teria de aprender com o outro, principalmente no que se refere ao objeto dessa pesquisa que é a realidade educativa e as práticas pedagógicas desenvolvidas nas escolas que funcionam dentro do cárcere de cada cidade.

E analisando de uma forma mais ampla, vemos que o Paraguai possui todos os problemas políticos e sociais do Brasil, juntos, misturados e com as inovações daqui. O país é pobre, tem carência em absolutamente todos os segmentos onde o governo deveria atuar, o que não é muito diferente da realidade brasileira

Um ponto muito positivo é que pelo Paraguai ser um país em expansão, há muita oportunidade para crescimento, principalmente no que diz respeito a abertura de negócios e investimentos no país, sem falar na menor quantidade de tributos que os paraguaios pagam em relação ao brasileiros.

Podemos perceber que a educação na prisão, cumpre uma função que é equalizadora, reparadora e qualificadora. $O$ que exige muito compromisso e responsabilidade dos profissionais envolvidos, que carregam como bandeira a resistência. Isso porque são muitos os fatores que tentam impedir que a educação entre no espaço prisional e faça o seu papel, que é a liberdade de expressão, emancipação e autonomia do indivíduo. O que deixa claro, que não se pode querer ou pensar em qualquer educação para EJA em prisões.

A lei não tem como fazer a parte dela sozinha, se não tiver quem exija ou provoque as autoridades competentes para sua aplicabilidade. Tanto no Colégio Professor George Modesto como o Centro Educacional de Tacumbú, está sendo necessário sensibilizar o governo, para que te fato haja investimentos para construção de espaços educativos mais apropriados na prisão. Para que, esses espaços possam contemplar uma maior quantidade de alunos, como no caso dos privados de liberdade em Assunção, que são muitos que querem estudar, mas não conseguem uma vaga na escola devido a capacidade da estrutura física da sala. É necessário também a 
oferta de uma merenda diversificada, já que ela é um forte atrativo para os internos estudarem.

É claro que a remição por estudo, também atrai muitos internos para estudarem, principalmente nas cadeias que não entra absolutamente nada, a merenda é de extrema importância. $O$ instituto da remição da pena, originária do direito penal espanhol, fora inserido na legislação brasileira através da Lei de Execuções Penais que previa a possibilidade de remição da pena por meio do estudo, como forma de instigar o sentenciado a participar das atividades desenvolvidas nos estabelecimento prisionais, com o fim de prepará-lo para o retorno ao convívio social.

É possível ver e ouvir também, de alguns coordenadores da área de segurança e dos diretores penitenciários, o quanto a educação ajuda na mudança de postura de alguns internos e como isso colabora na diminuição de conflitos entre eles e de rebeliões. Chegam a dizer que não conseguem visualizar o espaço prisional sem a oferta de educação, pois com certeza teriam muitos mais problemas do que já tem para administrar.

Os estados ainda não viram, ou não quiseram se debruçar sobre o assunto, para analisar financeiramente, o quanto eles ganhariam, se desse as condições mínimas adequadas, que estimule a maioria dos internos a estudarem e trabalharem. Além da economia financeira, visto o custo que é alto para se manter uma pessoa sob custódia do estado, estaria também evitando a superlotação carcerária

Faz-se necessário, então, que o Estado forneça meios suficientes para a evolução social dos presos, sendo a educação a força motriz desta evolução social. A Lei de Execuções Penais no Brasil, Lei ํㅜ 7.210/84, prevê instrumentos que possam vir a estimular os presos a aderir programas educativos, como é o caso da remissão de pena prevista em seu art. 126.

Mesmo reconhecendo que a prisão cumpre uma função social inegável, que é tirar da sociedade o delinquente, continuar querendo a permanência da falta de respeito a dignidade humana ou fingindo que não está vendo que a prisão vem sendo tratada 
como deposito humano e que só alcança na sua maioria os fracos e oprimidos, continuaremos com a convivência diária de atos de violência, pois como já dito por Freire, a desumanização causada pela opressão, impossibilita que uma pessoa alcance a sua emancipação ou libertação com a utilização de métodos que desumaniza e não respeita a dignidade humana.

Fortalecer a ideia da importância de se ter a educação dentro do cárcere e conscientizar os internos sobre outros tipos de liberdade, que não seja só a do corpo físico, é uma ação fundamental a ser desenvolvida pelo educador prisional. $E$ isso além de motivar, acaba contribuindo para uma reflexão, onde muitos começam a perceber que precisam ocupar os espaços da sala de aula. Apesar de aos poucos irem retornando aos bancos escolares, ainda são baixas as taxas de internos que estudam. Segundo dados fornecidos pela direção das penitenciárias, na escola de Salvador a média é de $20 \%$, e em Assunção, essa taxa é menor ainda, apenas cerca de $5 \%$ dos internos estudam.

A taxa baixa de alunos na escola da penitenciária em Assunção, foi justificada em visita a unidade, pela falta de interesse dos internos em estudar e ao mesmo tempo, de forma um pouco contraditória, pela capacidade estrutural da sala que não comportavam a todos que desejavam o retorno ao estudo. Mas na realidade, o que se percebe, segundo também o relatório do Ministério da Justiça de Assunção, é que a abordagem de reinserção da Penitenciária Nacional de Tacumbú praticamente não existe. Isto porque, é visível , como essa responsabilidade é deixado nas mãos das organizações religiosas.

Mesmo sendo uma penitenciária que recebe o maior número de processado e de pessoas que esperam para ser transferido para outros centros, essa transferência de responsabilidade acaba colaborando para exclusão dos internos da escola em Tacumbú , já que muitos tem crenças em outras religiões.E ainda que se convertam, os dados de 2013 , revelaram que dos 416 alunos matriculados em estudos da escola básica , 70\% desistiram. Porém dos que permaneceram na escola, o numero de residencias relatadas em alguns pavilhões foi de $12 \%$. 
Hoje, muito se discute sobre a incapacidade dos sistemas prisionais contribuírem para dar ao preso condições de participação na vida social. Por isso é de extrema importância que os estabelecimentos prisionais contribuam para dar ao preso condições de participação na vida social. A educação, com certeza, pode ter grande relevância para a formação da dignidade da pessoa humana, tanto assim que muitos dos alunos apenados começaram a vislumbrar novos horizontes, discutindo possibilidades de como e onde empreender, para poderem ganhar o seu sustento de forma honesta e deixarem a vida do crime para atrás. Alguns chegam a relatar sobre a vontade de darem continuidade aos estudos, cursando uma universidade para se qualificarem profissionalmente, melhorarem a sua condição de vida e poderem alertar outros jovens sobre a ilusão e as consequências em querer se ter dinheiro fácil.

Sendo assim, assegurar aos sujeitos que se encontram privados de sua liberdade, o direito à educação pode ser considerado um esforço importante no sentido de promover a construção de uma sociedade justa, onde no lugar da vingança, se faça de fato justiça, independentemente de raça, religião e posição social.

\section{REFERÊNCIAS}

ALMEIDA, Júlio Gomes e SANTOS, Rogério Queiroz dos. Educação escolar como direito: a escolarização do preso nas legislações penal e educacional. RBPAE v. 32, n. 3, p. 909 - 929, set./dez. 2016.Disponível em < file://C:/Users/Angela/Downloads/62926-290955-1-PB.pdf>. Acesso fevereiro de 2019.

BRASIL. Lei de Diretrizes e Bases da Educação Nacional. Lei 9.394/96. Brasília: Imprensa Oficial, 1996.

BRASIL. Lei o 7.210, de 11 de julho de 1984. Lei de Execução Penal Brasileira. Disponível em < https://presrepublica.jusbrasil.com.br/legislacao/109222/lei-deexecucao-penal-lei-7210-84>. Acesso em fevereiro de 2019. 
BRASIL. CONSTITUIÇÃO BRASILEIRA. Disponível em $<$ www.planalto.gov.br/ccivil_03/Constituicao/Constituicao.htm>. Acesso em fevereiro de 2019LEI № 9.394, DE 20 DE DEZEMBRO DE 1996. Lei de Diretrizes e Bases. Disponível em < http://www.planalto.gov.br/ccivil_03/Leis/L9394.htm>. Acesso em fevereiro de 2019.BRASIL. LEI № 12.433, DE 29 DE JUNHO DE 2011. Remição de parte do tempo de execução da pena por estudo ou por trabalho no Brasil. Disponível em <http:/wwww.planalto.gov.br/ccivil_03/_Ato20112014/2011/Lei/L12433.htm>. Acesso em fevereiro de 2019.

EZEOKEKE, Cornélius Okwudili. PENAS MAIS RÍGIDAS, JUSTIÇA OU VINGANÇA? 4ª Edição. Fortaleza: Premius,2013.

FRANCISCO, Wagner de Cerqueria e. "Homicídios no Brasil "; Brasil Escola. Disponível em <https://brasilescola.uol.com.br/brasil/homicidios-no-brasil.htm>. Acesso em 10 de fevereiro de 2019.

FREIRE, Paulo. Conscientização - Teoria e prática da libertação, uma introdução ao pensamento de Paulo Freire. São Paulo. Editora Moras LTDA. 1980.

FREIRE, Paulo. Pedagogia do Oprimido. 18ª edição. Vol.21.1988 . Editora: Paz e Terra.

FREITAS, Eduardo de. "Expectativa de vida dos brasileiros "; Brasil Escola. Disponível em <https://brasilescola.uol.com.br/brasil/expectativa-vida-dosbrasileiros.htm>. Acesso em 10 de fevereiro de 2019.

GADOTTI, M. e ROMÃO, J. E. (orgs.). Educação de jovens e adultos: teoria, prática e proposta. São Paulo: Cortez, 2011.

GUERREIRO, Pedro. A importância do trabalho e da educação para o apenado. Artigo publicado no Jus.com.br, 2014. Disponível em < https:/jus.com.br/artigos/32425/a-importancia-do-trabalho-e-da-educacao-para-oapenado >. Acesso em fevereiro de 2019 
JUNGES, Cíntia. Paraguai reinventa economia e vai de "primo pobre" a estrela da América Latina.

Disponível em https://www.gazetadopovo.com.br/politica/republica/paraguai-reinventa-economia-evai-de-primo-pobre-a-estrela-da-america-latina-6k7nm8k52792th72ue1028irw/> Copyright (C) 2019, Gazeta do Povo. Acesso em fevereiro de 2019.

LEGUIZAMÓN, María Lourdes. BARRIOS Andrea. RODRÍGUEZ, Alfirio. EDUCACIÓN EN CONTEXTO DE ENCIERRO EN PARAGUAY. Instituo para el Desarrollo e lá Inovacción Educativa. MERCOSUR.2009. Disponível em < http://aux.oei.org.py/idie.v2/pdf/contexto_encierro_final.pdf >. Acesso em fevereiro de 2019.

MENDONÇA, Heloisa. Apenas acesso à educação não é suficiente para reduzir desigualdade no Brasil, diz estudo. Disponível em: https://brasil.elpais.com/brasil/2018/12/15/politica/1544829880_024075.html> Acesso em fevereiro de 2019.

MONDARDO, Marcos Leandro. Identidades na fronteira (trans)territorial entre Brasil e Paraguai: olhares das relações de contato e de contraste. Disponível em: <http://e-revista.unioeste.br/index.php/temposhistoricos/article/viewFile/2215/1711>. Acesso em Janeiro de 2019.

PARAGUAY. CODIGO PENAL LEY №. 1.160/97. Disponível em < oas.org/DIL/ESP/Codigo_Penal_Paraguay.pdf> Acesso em Fevereiro de 2019.

PARAGUAY. CONSTITUCIÓN DE LA REPÚBLICA DE PARAGUAY, 1992. Disponível em jme.gov.py/transito/leyes/1992.html>. Acesso em Fevereiro de 2019.

PARAGUAY. Ley № 5.162/14, Código DE EJECUCIÓN PENAL PARA LA REPÚBLICA DEL PARAGUAY. Disponível em< https://py.vlex.com/vid/ley-n-5-162631747729 ou https://www.scribd.com/doc/284457739/Codigo-de-Ejecucion-PenalParaguayo-Ley-No-5162-14 >. Acesso em Fevereiro de 2019. 
PARAGUAY. Constitución de la República de Paraguay, 1992. Disponível em $<j m e . g o v . p y /$ transito/leyes/1992.html>. Acesso em Fevereiro de 2019.

RIVAROLA, Domingo M. La reforma educativa en el Paraguay. Series Políticas sociales. CEPAL ECLAC. División de Desarrollo Social. Santiago de Chile. 2000. Disponível em $<$ https://repositorio.cepal.org/bitstream/handle/11362/5972/S00090772_es.pdf?sequ ence $=1$ \&isAllowed $=y>$. Acesso em fevereiro de 2019.

SILVA, Iranilton Trajano da. Inovações trazidas pela Lei N. ${ }^{0}$ 12.433/2011 ao instituto da remição da pena e a omissão legislativa do Art. 127 da LEP.15 jul.2013.Disponível em < http://www.conteudojuridico.com.br/artigo,inovacoes-trazidas-pela-lei-no124332011-ao-instituto-da-remicao-da-pena-e-a-omissao-legislativa-do-art-127da,44364.html>. Acesso em fevereiro de 2019.

SOUSA, Madson Thomaz Prazeres. Algumas linhas sobre a Lei ํㅜ 12.433/2011 e suas alterações no instituto da remição. 19 out. 2011 Disponível em $<$ http://www.egov.ufsc.br/portal/conteudo/algumas-linhas-sobre-lei-n\%C2\%BA124332011-e-suas-altera\%C3\%A7\%C3\%B5es-no-instituto-daremi\%C3\%A7\%C3\%A30>. Acesso em fevereiro de 2019.

Enviado: Abril, 2019.

Aprovado: Outubro, 2019. 